\title{
Bonify 1.0: evaluating virtual reference collections in teaching and research
}

\author{
Gary Nobles ${ }^{1}$ (D) $\cdot$ Canan Çakirlar $^{2}$ (D) $\cdot$ Pjotr Svetachov $^{3}$
}

Received: 10 March 2019 / Accepted: 27 June 2019 / Published online: 1 August 2019

(C) The Author(s) 2019

\begin{abstract}
Accessibility to zooarchaeological reference materials is a key hurdle when determining species classification, particularly in cases where the differences between two species (e.g. sheep and goat) are nuanced. Bonify is a pilot platform allowing the virtual comparison between 3D virtual animal bone models and zooarchaeological specimens. Two technologies were case studied, online web presentation and augmented reality. The two methodologies were tested by a selection of students and domain professionals. While the physical reference collection was viewed as the most usable, it was limited in terms of accessibility; the second best option turned out to be the web based interface while the augmented reality option suffered in terms of its usability. The web interface is available at www.digitalbones.eu.
\end{abstract}

Keywords Zooarchaeology $\cdot$ Taxonomic identification $\cdot$ Virtual reference collections $\cdot$ Teaching $\cdot$ Research $\cdot$ Virtual reality $\cdot$ Web graphics library

\section{Introduction}

Zooarchaeological reference collections are continuously developing, obtaining new specimens and rethinking how specimens are communicated to researchers and students. Initially, scientific communication was enabled through textual description and drawings (e.g. Schmid 1972); later, photography was added to the documentary media (e.g. Zeder and Lapham

Electronic supplementary material The online version of this article (https://doi.org/10.1007/s12520-019-00898-1) contains supplementary material, which is available to authorized users.

Gary Nobles

garynobles20@gmail.com

Canan Çakirlar

c.cakirlar@rug.nl

Pjotr Svetachov

p.svetachov@rug.nl

1 Research Center for Anatolian Civilizations, Koç University, İstiklal Caddesi No: 181 Merkez Han 34433 Beyoğlu P.O.B, 260 İstanbul, Turkey

2 Groningen Institute of Archeology, University of Groningen, Poststraat 6, 9712 ER Groningen, The Netherlands

3 Center for Information Technology, University of Groningen, Nettelbosje 1, 9747 AJ Groningen, , The Netherlands
2010). Today, digital models are becoming a further source for comparison. The role of digitisation of reference collections has already been preempted; in 2004, at the international conference on the European electronic Reference Collection, the concepts surrounding reference collections were collected in a single edited volume (Lange 2004). Within this, there was a general consensus that

"European reference collections of the future will inevitably be digitally based ... [and] ... electronic access cannot function as a complete replacement for the physical examination, by sight and touch, of type specimens" (Richards 2004:85; see also Orton 2004: 32; Nieuwhof 2004).

Following further technological innovation, reference collections have begun to benefit from 3D scanning (Niven et al. 2009) and be disseminated through the web (Betts et al. 2011).

Today, nearly any surface or object can be captured digitally; the technology is rapidly maturing; alongside, this scholars are beginning to think again about the role that digital technology plays in research and education (Luckin et al. 2012; Deb and Ray 2016). The resurgence of VR and related experiential media have often engaged with the broader public and general interest; the valorisation has been mostly external 
to those actually active in the field of interest. While there are those exploring emotive discourse through specific veins such as archaeogaming (Eve 2012; Perry et al. 2018; Reinhard 2018) and related terms, the functional practical, in some respects mundane, applications require serious development. Forte notes that in general, we are still led by technological determinism and what he assigns as the "wow era" where the technology and act of model creation take president over the research questions and their application (Forte 2000, 2014, p116). If one is to only pursue this recourse, then the value digital/virtual/cyber archaeology offers itself and the broader scientific disciplines becomes diminished.

While adhering to this perspective, this paper has approached digital technologies from a specific zooarchaeological problem. How can we apply digital technologies to achieve a more robust methodological framework when it comes to the reliable identification of animal remains. Focus for this research pertained to a particular problem, known colloquially as the Sheep/Goat problem.

\section{The sheep-goat problem}

Sheep (Ovis sp.) and goat (Capra sp.) bones and teeth, whether modern or fragmented remains from thousands of years ago, are notoriously difficult to distinguish. Scholars have been trying to establish osteomorphological criteria to distinguish them for decades (Prummel and Frisch 1986; Boessneck et al. 1964; Payne 1985; Helmer and Rocheteau 1994; Halstead et al. 2002; Zeder and Lapham 2010; Zeder and Pilaar 2010; Gillis et al. 2011). 'Sheep or goat'? is still one of the most common questions you will hear in conversations between practitioners of zooarchaeology when looking at zooarchaeological material. Opinions are in contention, especially if they do not have a reference collection. Few researchers have the opportunity to test their sheep/goat identifications using ancient DNA techniques or collagen peptide mass fingerprinting (zooarchaeology by mass spectrometry: commonly known as ZooMS) (Pilaar Birch et al. 2018). It is common practice to refer to sheep and goat remains as sheepgoat ignoring any distinction between the two and thus prematurely ending the debate. This is despite the fact that ethnographic, historic, ecological and archaeological research have repeatedly demonstrated that sheep and goat, two distinct species, have different social, economic, cultural meanings, management requirements, and environmental impact (Ryder 1983; Redding 1984; Zeder and Hesse 2000; Vigne and Helmer 2007).

\section{Teaching and research}

Zooarchaeological reference collections are crucial to enable reliable research and fulfil the didactic requirements in the training of the next generation of zooarchaeologists. The reference collection is enshrined in pedagogic practice. The method of looking at an archaeological bone, comparing it with recent (mostly modern) skeletons of known species sounds like a straightforward procedure. However, it requires a lot of knowledge, skill, experience, to be able to assign an archaeological specimen to a species (or some higher taxon), and then conduct osteomorphological analysis. Above all, an extensive reference collection both at the training phase and in practice is fundamental scientific requirement. This is especially true when looking for morphological distinction between closely related species, such as the sheep and goat which are in the same family (family of Bovidae). As the number of skeletons representing a species increases, trained researchers are able to eliminate intra-species, individual or breed differences in skeletal morphology, discerning osteomorphological criteria valid for a species as an entire biological unit. These methods are not limited to zooarchaeology, but they are used in research settings concerning biology as well. For example, marine conservation biology relies heavily on the identification of small fish bones and teeth found in the stomachs of larger fish or marine mammals.

\section{The reference collection}

A good reference collection takes decades to build. In some cases, they contain extinct animals or regional populations whose biodiversity is represented by their physical skeletal remains alone. Such collections are unique, making them difficult to access. Accessibility is also dependent on lab opening hours, limited lab space (space for limited material), staff availability etc. This is out of line with interests in democratising higher education and science. Moreover, most zooarchaeological analysis is conducted in the field (palaeontological, archaeological or biological), usually in remote locations. When excavating abroad, it is not always possible to bring the assemblages to study them alongside a good reference collection due to political and logistical constraints. Current limitations on the accessibility to good collections and the possibilities of 3D technologies make it clear that digital collections are the future direction. The issues of accessibility and democratisation of science have been raised previously in relation to the rationale for the virtualisation of reference collections (Sullivan and Childs 2003, 45-53, Maschner and Schou 2013).

Within this context, a team of specialists from Zooarchaeology, Digital Archaeology and the department of Information Communication Technology (ICT) collaborated under the remit of the University of Groningen's Center for Digital Humanities within the Exploratory Projects initiative. The purpose of this programme was to support pilot projects to explore the use of digital media and techniques within the domain of the humanities. The project was titled Bonify, not only due to the play on the word 'bone', but the deeper 
associated meaning "To convert into, or make, good" (YourDictionary 2019), converting from the physical medium to the virtual. Bonify's aim is to explore, evaluate and demonstrate the potential of digital resources for use in teaching in higher education and scientific research. The pilot was limited to a maximum of 1 year and subject to a modest budget. This had to cover equipment costs and staff time. In light of the restrictions and in order to capture a sufficiently broad dataset, the models were captured rapidly and assessed by the zooarchaeologists regarding specific diagnostic criteria.

\section{Creating a digital collection}

To begin, to approach this topic, a virtual reference collection was required; diagnostic sheep and goat bones were selected from the Groningen Institute of Archaeology's zooarchaeological reference collection. The sex, age, breed, country of origin data of the specimens used are provided in the Supplementary Material Table. The bones had a high degree of reflectivity due to the repetitive handling; this could influence the quality of the 3D scans, so they were cleaned with acetone before scanning.

A Structured Light Scanner (the David SLS-2) was used to scan the bones; for the long bones (femur, radius etc.), 6-8 scans were taken on an automated turntable, the bones were held upright in a cup of sand and rotated through $360^{\circ}$. Upon completion, the bone was flipped and the process repeated, (see Fig. 1). On occasion, complimentary scans were taken to fill in missed areas, due to obstructions and overhangs. The scans were aligned and post processed in David's native software. To reduce the effect of ambient light, a 'black box' was built, an aluminium frame covered in black sheeting encompassing a volume of $1 \mathrm{~m}^{3}$. A single $360^{\circ}$ round of scanning took up to 3 minutes, resulting in a model in under 10 minutes. The smaller bones were easier, placed directly on the turntable without support; once scanned, the bone was flipped and the other side scanned using the same methodology as above. Minimal cleaning of the scans was required mostly due to background noise; this was removed through manual selection. For increased time efficiency, an 'assembly line' was set up scanning each long bone once before repeating the process. The remaining bones, such as scapula and mandible had to be approached on a bespoke basis involving manual scanning. Scanning of these more geometrically complex bones took longer, up to a maximum of 30 minutes.

The system can acquire models accurate to $0.01 \%$ of its height; it requires the use of calibration panels; the size of the panel is dependent on the object to be scanned. Two calibration panels were used, the $30 \mathrm{~mm}$ and the $60 \mathrm{~mm}$; this information is presented in the supplementary table. The structure light scanning (SLS) method was chosen due to its lowcost and high detail, while many projects utilise photogrammetric techniques for the recording of artefacts (see for

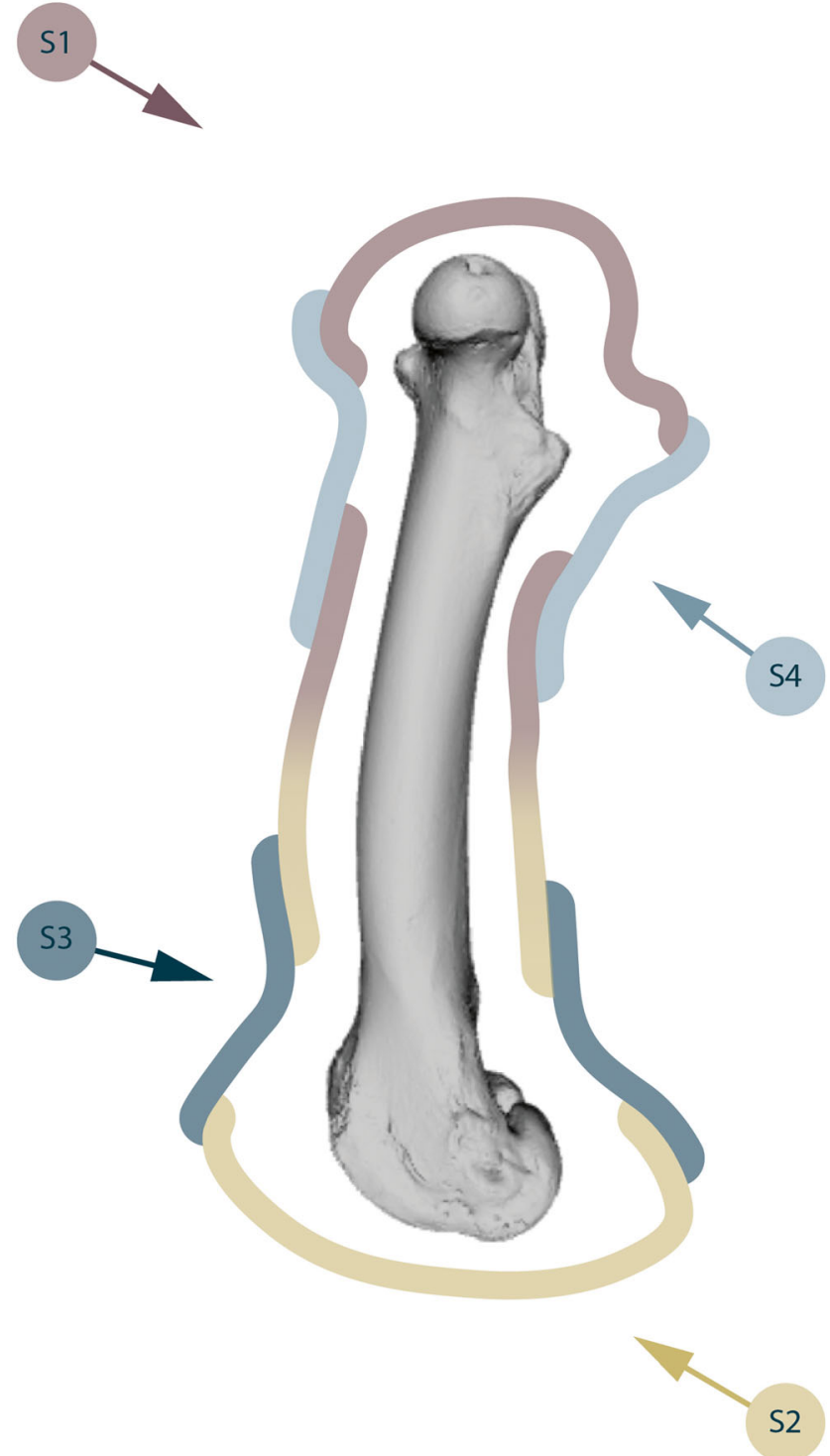

Fig. 1 A representative overview of the scanning process indicating the location of the scanner, it's focus and its coverage for a 360 vertical scan

instance Kersten and Lindstaedt 2012, Nicolae et al. 2014). The SLS method is far quicker when processing time is included in the timings. In comparison, SLS generates a higher resolution, more accurate and thus better result (Alby et al. 2009). SLS also allows an instant review of each scan during the process negating the potential of a poor composite result at the end of the processing workflow or the need to revisit materials for further data capture. For this project, the geometry was of greater importance than the photographic derived texturing, while the textures were captured, they were left unprocessed since they play no further role in this project. Textures would make the bones more aesthetically pleasing but the information relates more to the post-maceration processes rather than diagnostic details; the inclusion of colour can include staining which can detract from the specific details which are crucial for an accurate identification. 


\section{Visualisation}

Once digitised, the bone scans can be visually presented through various media such as web browser (WebGL) technology, virtual and augmented reality, and replicated through 3D printing as a form of physicalisation (see Jansen et al. 2015). Since accessibility was a prime consideration of the project, high-cost solutions, although available, were avoided in an effort to retain financial accessibility. The implementation through high-end technological equipment, like Oculus Rift and the Z-space, would have put Bonify beyond a realistic budget for the target audience. Instead, smartphone technology was adopted due to its already wide adoption and relatively low cost, only requiring a compatible headset.

\section{Augmented reality}

Smartphone-based virtual reality was chosen as the most financially accessible technology and due to its portability. Augmented Reality (AR) was decided upon since it allows the researcher to view both the digital model and the physical bone through the smartphone. The headset configuration was comprised of the Samsung S7 with HeadgearVR; it was also later tested using a Samsung S8 model which proved to be more dependable. The Unity3D gaming engine with the Vuforia libraries was the development platform of choice. This technology requires the use of a card or marker with an embedded code; as seen in Fig. 2, a logo can be integrated into the design for identification and/or marketing purposes. While any marker could be used, VUmarkers were chosen and the cards were printed through an online custom playing card company. For ease of display, the resolution of the digital models had to be reduced to allow manageable file sizes.

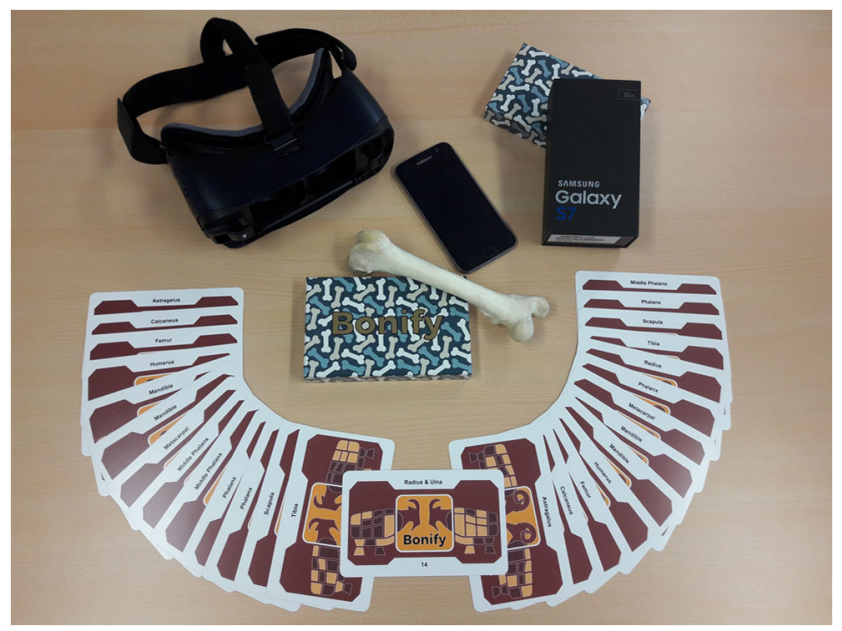

Fig. 2 The Bonify AR equipment: headset, smartphone, cards, reference bone
WebGL

The Web Graphics Library (WebGL) approach enabled the greatest level of accessibility directly through the web browser. The 3D Heritage Online Presenter (Potenziani et al. 2015, 3dhop.net) was used; unlike the AR headset, this technology allows the presentation of the models in full detail; this is achieved by first converting the models into the Nexus format which presents multiple Levels of Detail (LoD); thus, the presented model is partitioned into parts with different LoDs depending on the perspective of the viewer; this ultimately means the full detail can be retained without compromising on presentation quality.

The 3D HOP platform comes ready with built-in tools for zooming, lighting and slicing. Bonify made use of these defaults but adapted the code, wrapping it in Php with the addition of javascript. This enabled the selection of different bones through various pullouts and dropdowns. A second button was added to enable a split screen view allowing the user the ability to display two bones, either two of the same species or one of each (see Fig. 3). This is available online at www. digitalbones.eu.

\section{D printing}

A selection of the bones were $3 \mathrm{D}$ printed to complete the cycle from physical object to digital object to physical reproduction. These were not formally tested alongside the other media, since a physical collection, even a reproduction, has the same limitations as mentioned at the beginning of this paper. However, one caveat can be considered in relation to the reproduction of rare and fragile objects which cannot be handled. In this instance, the bones were printed using LCD resinbased technology which reproduced the bones at submillimeter resolution.

\section{Questionnaire results}

The bonify interfaces were tested on a range of professionals: students, B.A., M.A., Ph.D. and generic university education. This took place in small specialist groups at the University of Groningen's zooarchaeology lab, the annual professional zooarchaeologists' meeting at the Dutch State Service for Cultural Heritage (RCE) and at the University of York. All three groups ranged from bachelor level through to those with PhDs. All participants had at least some prior exposure to zooarchaeological collections. The age range of the respondents was between 22 and 63; 9 were male while 13 were female. In terms of the respondent's level of education, either achieved or currently taking, a bachelor level study $(n=2)$, a master level study $(n=11)$, a PhD level study $(n=5)$ or generic university education $(n=4)$. In total, 22 questionnaires 


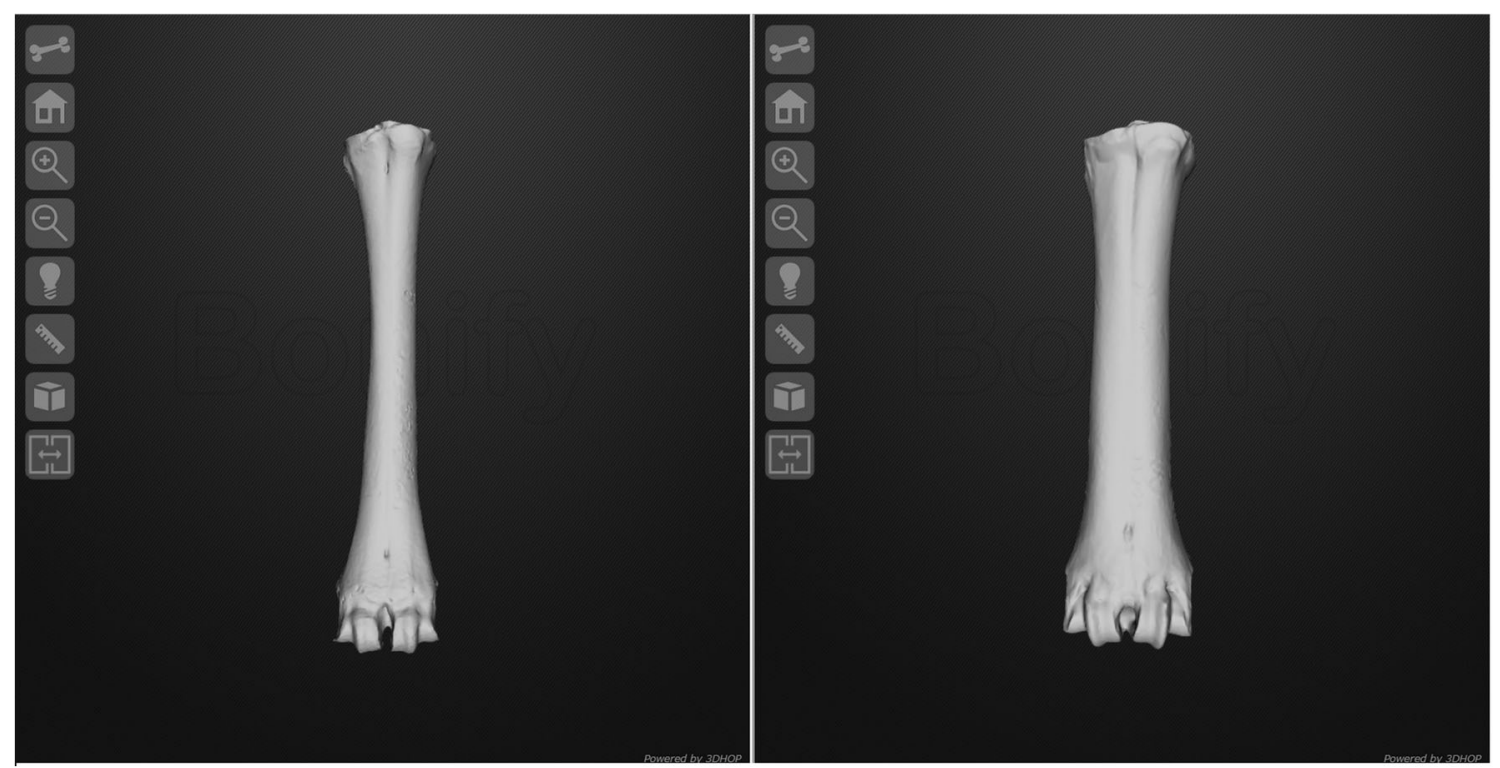

Fig. 3 A screenshot of the Bonify duel view interface displaying a sheep metacarpal (left) and a goat metacarpal (right)

were submitted; while the majority were complete, a few respondents were unable to test the full range of interfaces resulting in partially completed forms. This data was included in the final analysis, but explains why in some cases the number of respondents is less than the full 22 .

The questionnaire was designed along the Likert scale (Likert 1932, Bertram 2016); this was to allow for the application of a Whitley-Mannley test for significance; since the response number is less than 30 , it would be inappropriate to apply the hypothesis testing. The questions on the one-to-five Likert scale asked the respondents about the user-friendliness and the usefulness of the interfaces; they were also asked to provide an overall rating on the same one-to-five scale. When respondent's rated their response as two categories, for instance neutral and positive, the score is split giving a value of 0.5 to both categories. The respondents were also asked to answer the same questions reflecting upon their experiences of zooarchaeological reference collections; this was to serve as a baseline assessment to allow reflection on the virtual reference collections.

In addition, a series of free-text questions were presented asking the respondents to reflect how the user experience could be improved, when they would make use of it and to what degree the new technology could replace a physical reference collection. A series of follow-up questions asked the respondents' opinion regarding the development of a virtual reference collection: their focus, how it would aid in teaching and research, and allowing them to list any comments, questions or concerns. Finally, they were asked to choose which virtual interface they preferred: both, AR, web, neither; the physical reference collection was intentionally omitted as an option.

\section{Setting the baseline}

Opinions were gathered regarding respondent's overall perception of the current state of the physical reference collections they have at their disposal. Responses ranged from neutral to very positive, although highly skewed to the very positive category (Fig. 4). In terms of the user-friendliness, the physical reference collection received a good review with all but one neutral respondent rating it was positive to very positive. In terms of usefulness, the response is nearly unanimous with only 1.5 respondents rating it useful with the remaining 13.5 scoring in the very positive category. This sets a very high baseline which appears near impossible to improve upon; it demonstrates the crucial role physical reference collections play in zooarchaeological teaching and research for data collection and interpretation. While there can always be improvement, the responses indicate that these reference collections can be considered as near excellent and user-friendly.

Before analysing the results of the new technology, a firm baseline needs to be set regarding the usability, usefulness and the overall perception researchers have towards the physical collections. Respondents were asked (Q1) how user friendly they viewed the physical reference collections they access, (Q2) how useful they viewed it and (Q3) to give it an overall rating. The results signify a range from neutral to very positive, with very positive being the dominant view. When investigated in terms of the level of education, the general pattern is reflected; therefore, it can be concluded that whatever the level of study or expertise reference collections are vital for effective identification of archaeological animal remains. The respondents were asked to comment on the usability of reference collections; more specimens were the main request, indicating the requirement for ongoing specimen collection. In 

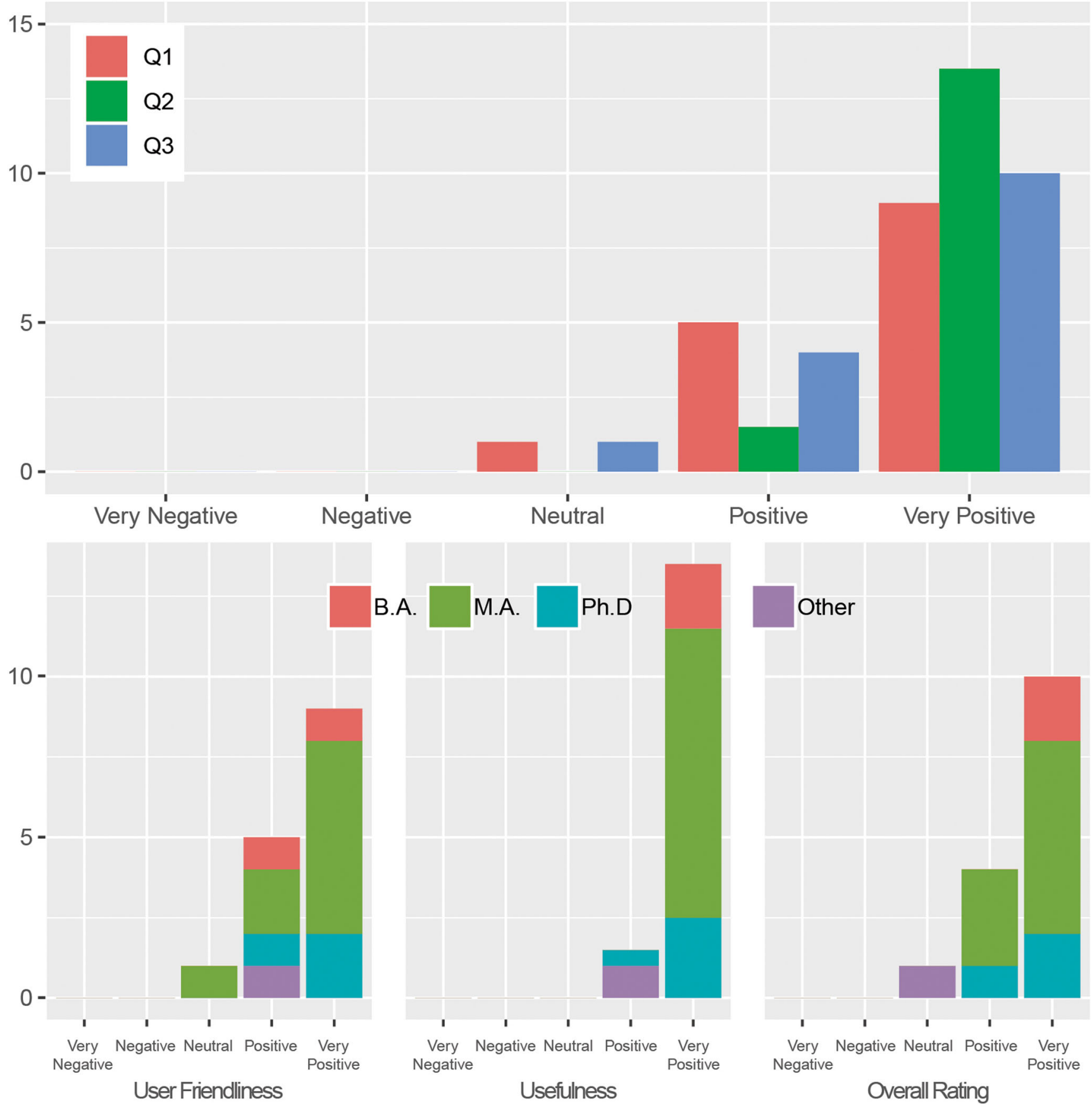

Fig. 4 Responses to the physical reference collection. Top: (Q1) user friendliness, (Q2) usefulness and (Q3) an overall rating. Bottom: Divided by level of education

terms of when the researchers were most likely to make use of the collection, it was in the lab during analysis. However, accessibility was a key concern, 'when accessible' was a common remark. One respondent went further stating the need for a field reference collection, but the cost in terms of transport and duplication of a reference collection was problematic. On reflection, the responses could be biased; since zooarchaeologists are mainly trained to analyse in labs, fieldwork-based analysis is less common.

\section{Augmented reality}

The Augmented Reality smartphone app was tested by 18 of the respondents; overall (Fig. 5), the responses to the Augmented Reality interface ranged between negative and very positive. The user-friendliness was viewed as positively; however, three of the respondents had negative feedback; this was due in part to the camera delay causing some participants nausea and the comfort of the headset. This is a key concern if 

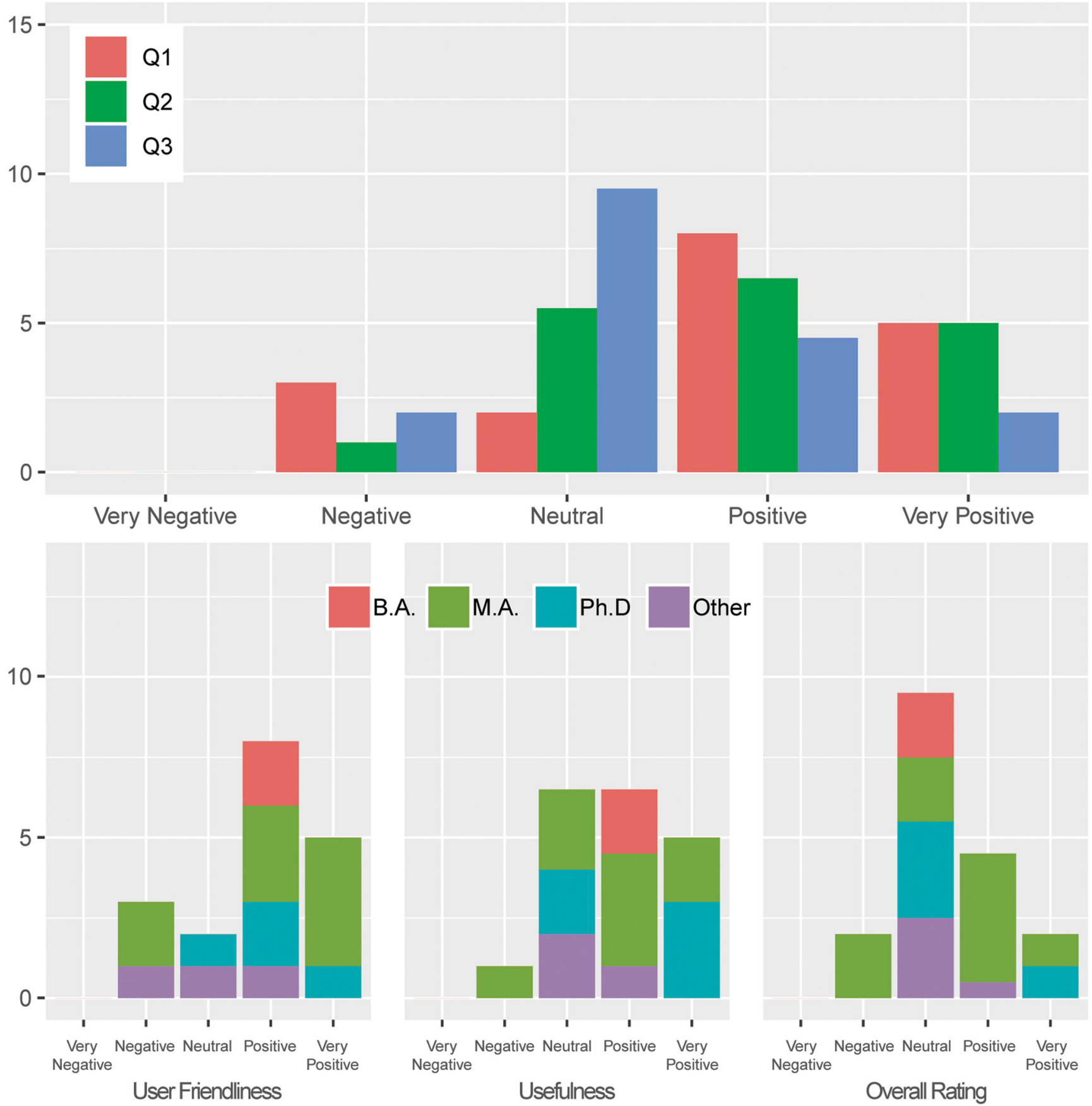

Fig. 5 Responses to the Augmented Reality app. Top: (Q1) user friendliness, (Q2) usefulness and (Q3) an overall rating. Bottom: divided by level of education

researchers were to use this on a daily basis. The usefulness of the AR received slightly more positive responses, yet the neutral responses were similar when weighed individually against the positive responses. The overall experience was dominated by the neutral responses $(52 \%, n=9.5)$. This is below the baseline set by the physical collections.

If the results are broken down by the level of the user, it appears that the $\mathrm{PhDs}$ are critical regarding its application, whereas MA/MSc's display a broader variation in terms of the positive and negative spread, albeit skewed positively. The usefulness of AR by bachelor level is viewed as positive, masters level responses spread from negative through to very positive. The $4 \mathrm{PhDs}$ illustrate a 60:40 split between very positive and neutral. The respondents indicated that the AR would be of best use in the field, this extends to situations where a physical reference collection is not accessible. A few remark on its application to teaching which is returned to in the discussion. Suggestions for improvement included a 
dual model approach, allowing more than one bone to be visible. In terms of the comfort of use many of the respondents reported feelings of discomfort, motion sickness, dizziness, headaches and eye strain after a short period of use.

\section{The web platform}

The web platform was tested by all 22 respondents, overall (Fig. 6) the responses ranged from neutral to very positive, with only one negative response. In terms of the user friendliness (Q1), the majority (ca. 80\%) were in the positive categories; the usefulness saw equally high positive responses, and in overall terms $(\mathrm{Q} 3)$, the web application received high positive feedback.

When assessed by the level of education of the respondents, it is demonstrated that those with an education to the Bachelor and Masters level exhibit a stronger positive opinion than those with a $\mathrm{PhD}$ level who are a little more conservative in their opinions, but still positive. While the user friendliness gave positive results, the more important question regarding

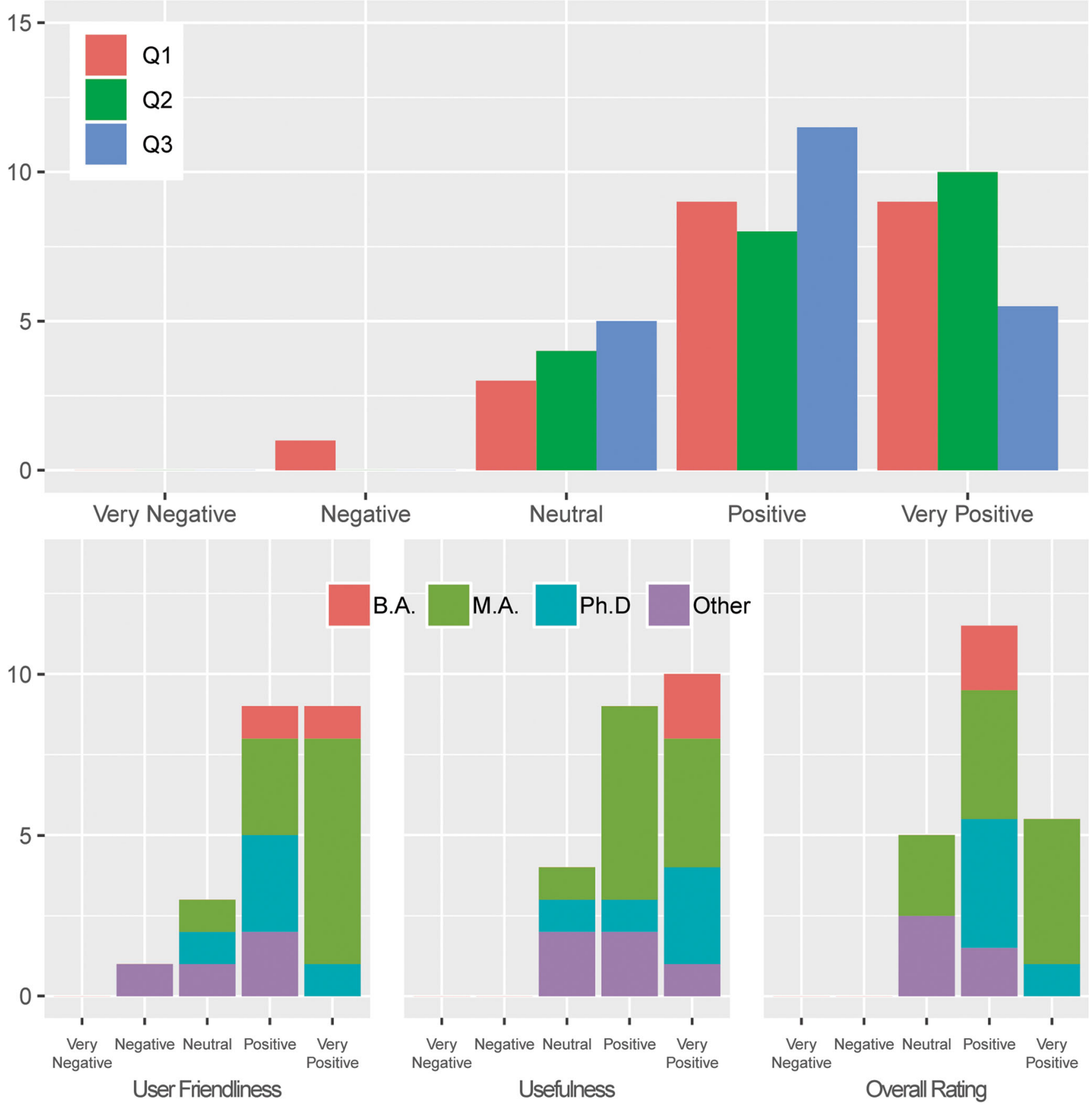

Fig. 6 Responses to the WebGL app. Top: (Q1) user friendliness, (Q2) usefulness and (Q3) an overall rating. Bottom: Divided by level of education 
the usefulness and the overall perception of the platform indicates a good positive reaction, although there is some neutrality.

All of the above results have been presented on face value. Statistical analysis of the populations was planned, particularly through a Mann-Whitney test, to assess the views of the various education levels. It was not applied since it is not statistically valid to do so with populations of less than 30 .

\section{Further questions}

Two statements were put to the respondents; they were asked which they most agree with in regard to the two types of interface:

(a) The interface replaces the need for a physical reference collection.

(b) The interface is complementary to the physical reference collection.

(c) The physical reference collection is fine as it is, a virtual reference collection is not needed.

For the web interface, the responses were unanimous; it was viewed as complementary to the physical reference collection (option b). Opinions of the AR interface were nearly the same, with only one respondent stating it was not needed (option c).

Regarding the application of the interfaces, the respondents were asked to complete the following sentences with the four options provided:

The interface is ...

(a) Most applicable to research

(b) Most applicable to teaching

(c) Most applicable to both teaching and research

(d) A novelty and not applicable to research and teaching.

For the web interface, the majority $(n=17)$ stated both (option c); the remaining were split between solely research $(n=1)$ and teaching $(n=3)$; one declined to answer. None viewed it as a novelty. This is not the case for the AR where two viewed it as a novelty; the majority saw it as a teaching tool $(n=7)$; some saw its use in research $(n=3)$, and some saw it as both research and teaching $(n=3)$, the remainder declined to answer.

When asked if they would like to take an active role in digital archaeology, 15 stated yes, 3 were unsure and 4 answered no. When asked if digital methods should be applied in teaching, one responded with maybe while the remainder answered yes. When asked which platform, be it the AR or the web interface, only one opted for the AR interface, three saw a place for both, whereas the majority choose the web interface $(n=12)$.

\section{Discussion}

The results of the questionnaire are revealing and in some ways unexpected. The high baseline set by the physical reference collection is unlikely to be surpassed by alternative methods available currently; however, it was enlightening to see the range of views from this relatively small selection of specialised individuals. While the number of respondents is far too low to offer any statistical significance, we can use it to guide the general discussion. For zooarchaeology as a research and taught discipline, the visualisation technology is still maturing. The contrast of the opinions between the AR and the web-based platform indicates that mobile smartphonebased AR for education and research, in this context, does not completely stand up to the hype.

While some respondents liked the AR experience, others had negative responses; this approach, therefore, does not create a platform which facilitates open access to all whom would wish to make use of it. The AR headset is susceptible to environmental and psychological factors. The amount of ambient light affects the detection of the cards; the lag of the camera and its resolution can result in motion sickness, disorientation, headaches and eye strain, factors which will not benefit the working conditions of researchers and students who aim to use the technology over prolonged periods of time. This is not to say that AR does not have a role to play, particularly, since many of the respondents thought it could have an education role. Bonify AR's platform has been successfully used at various outreach events such as the 95th anniversary of the Groningen Institute of Archaeology, Noorderzon performing arts festival and in conjunction with Groningen University's Reality Center to demonstrate technological possibilities. AR has demonstrated itself to be engaging for young and old, the experienced and the novice. However, this enthusiasm is more about the technology than the content. Therefore, it is limited in its application since it aims to be a university level research orientated and educative platform.

In contrast, the web-based platform fared far better; both the researchers and students found it to be a good alternative to the reference collection on occasions when the physical reference collection was not available. It has the advantage of maturing WebGL HTML5 technology and multi-resolution display methods which allow the ca. $1.5 \mathrm{~GB}$ files to be seamlessly displayed without substantive lag. The web interface is not perfect; it was deliberately minimalistic; various suggestions have been put forward for future development. However, this media experience successfully facilitated collaboration and discussion of the zooarchaeological differences between reference specimens. The educator can present and discuss the 
models on a screen and reach a large number of students without the need of headsets.

On reflection, it would appear that at this moment for the zooarchaeologist, the implementation of a digital reference collection is better suited to WebGL technology. The valorisation of these materials on the academic and public level is important; there is no reason however why an internet browser-based platform cannot also allow for the integration of VR technology in the near future.

To present Bonify as a new venture into this technology would be a misnomer; there are other platforms like Sketchfab, VZAP, Morphosource and aves3d, (Claessens et al. 2009; Maschner et al. 2011; Boyer et al. 2017; Erolin et al. 2017) amongst many others, which present the 3D models. Bonify, however, is specific to a particular research problem, rather than a repository which the data is presented for a specific audience, that of the zooarchaeologist. It is also unique as it is the only one which approaches from a specific research problem orientated position, the sheep/goat problem.

Archaeology is increasingly using Sketchfab as a 3D model valorisation platform, but it is highly restrictive in terms of model resolution; other systems like Potree, iTowns, LoPoCs and 3D HOP (Potenziani et al. 2015; Picavet et al. 2016; Schuetz 2016) present the archaeologist with far more versatility for presenting and communicating their data in high resolution. Sketchfab benefits from being a quick and simple, convenient platform, but that does not detract from its deficiencies. Archaeological and heritage objects on the platform are mixed with fantasy objects. There is little to no authority regarding the authenticity of objects. The metadata is related only to that of the models' geometric characteristics, rather than the method of data capture, purpose and geographic location. Other academic platforms like MorphoSource are presented as a repository, a store and a library of specific models; it aids the sharing of knowledge through digital-fossil specimens; it is generic in its outlook which is both a positive and a negative evaluation.

This returns us to the long debated topic of 'push-button' methods and the role of the Digital Archaeologist (Kvamme 1999; Huggett 2004; Lock 2009). Some of the respondents wanted a greater role in the acquisition of the 3D models; they wanted to take responsibility for the digital reference collection, just as they would when creating and maintaining a physical collection, whereas other respondents were not wanting a more active role. This presents a question, while the humanities undergoes this 'digital-turn', perhaps zooarchaeology—and the broader archaeological discipline - still views the digital as a specialism; in short, it is. However, it is no ivory tower. Obviously, it would be irresponsible to expect zooarchaeologists that are untrained in the digital techniques to apply them to their field. But, forging cross-disciplinary long-term projects between the subject specialists, digital archaeologists and ICT professionals which involves two-way knowledge exchange can only serve to positively impact on those involved.
Bonify, being in its infancy is focused on a single question, a single audience, yet this need not be the case. While it is possible to store a single digital object in a database, it is also possible to disseminate the object infinitely; there is no limitation to the amount of discipline-oriented interfaces which could be developed to serve various academic communities. The Bonify platform is designed to suit zooarchaeologists, but the crossover with biology, medical sciences, in school teaching and many others is clear to see. Reference collections are becoming digitised increasingly in terms of the data relating to the specimens held (see for instance Çakirlar et al. 2016, Fairnell and Orton 2017), but the digitisation of the physical objects appears to be less of a priority. As demonstrated in this paper, there is no reason why fully digital representations should not become commonplace in years to come.

\section{Conclusion}

Archaeology and heritage is going through another phase of 'pretty pictures'; this occurred previously during the 2D GIS revolution with the making of 'pretty maps' before we moved forward into analytical discourse. Now the 3D developments are going through the same process where the vast majority of research is focused towards valorisation. While an awkward but apparent necessary rite of passage, the bias between pure visualisation and more productive frameworks is unequivocal. This has been recently demonstrated in respect to the rise of $3 \mathrm{D}$ visual technologies contrary to $3 \mathrm{D}$ spatial analysis (see for instance van Leusen and Nobles 2018). There is a clear question floating over many scientific disciplines, how can it use this re-emerging technology for scientific purposes beyond valorisation and entertainment-based visualisation. While Roussou et al. 2019 are an exception, there is a clear absence of scholarship in this arena which has already been noted by Champion (2016); how virtual technologies can be adapted to suit classroom teaching and scientific research is an area which requires further investigation.

In this case, it is clear from the results of the questionnaire that no digital proxy will be able to substitute for the relevance of the physical reference collection. This was never the aim of this project; the purpose was to discover if, or to what degree, a digital reference collection could be used to allow greater universal access to physical collections. While WebGL is currently the preferred technology by the professional, the platform should not detract from the necessity of content creation. Once objects are digitised, they can be presented in a number of ways and to various audiences. However, such platforms become unsustainable if no-one is using them. To become usable, digital cultural heritage needs to reach a critical mass; for a zooarchaeological platform, this involves the scanning of many more bones, approaching the specimens from not only a data capture perspective but a data quality perspective. This 
should also involve the capture of variation in specimens, targeted features like bones displaying certain pathologies and deformities.

On a more generic level, we need to test the suitability of new technology to working habits and teaching efficiency for communicating ideas and concepts to students. Some working in the technoscape are trying to convince the masses that VR and related technology will be the future. As scientists, we have to be prepared that VR may not be applicable in all circumstances and that we as researchers and educators may have to buck the populist trend when faced with the choice of multimedia presentation. Whereas, it is clear to those with a critical overview of the technoscape that VR technologies are only one part of the range of technological solutions which are open before us. We should not, therefore, be led by technological determinism, but inversely let the research guide the development of future technology. The discipline-oriented researchers, like zooarchaeologists need to converse with the digital archaeologists and vice versa. Together, we need to standardise the problems we all face, present and road-test potential solutions whilst resisting the lure of the technological 'wow factor' and mediate the technological hype against the productive reality.

Acknowledgements We would like to thank all those who participated, passed comment and helped in some way to make Bonify a reality. In particular, the efforts of Hans Christian Küchelmann in the preparation of the specimens, Esther Scheele for helping select the specimens, her critical eye, and sourcing the sand, Nynke de Boer for presenting Bonify at the International Council for Archaeozoology (ICAZ). This gratitude extends to all those who tested and filled in the questionnaire and those persons and organisations who permitted us to demonstrate Bonify. In particular, the Dutch State service for cultural heritage (RCE), David Orton of York University and the students of the Groningen Institute of Archaeology (GIA). We would also like to extend our gratitude to Groningen University's Center for the Digital Humanities for funding this research as well as the two anonymous reviews for their useful comments.

Funding This study was funded by the University of Groningen's Center for Digital Humanities through the Exploratory Projects.

\section{Compliance with ethical standards}

Conflict of interest The authors declare that they have no conflict of interest.

Open Access This article is distributed under the terms of the Creative Commons Attribution 4.0 International License (http:// creativecommons.org/licenses/by/4.0/), which permits unrestricted use, distribution, and reproduction in any medium, provided you give appropriate credit to the original author(s) and the source, provide a link to the Creative Commons license, and indicate if changes were made.

\section{References}

Alby E, Smigiel E, Assali P, Grussenmeyer P, \& Kauffmann-Smigiel I (2009). Low cost solutions for dense point clouds of small objects:
Photomodeler scanner vs. David Laserscanner. 22nd CIPA Symposium, Kyoto, Japan, 15(17), 71-76.

Bertram, D. (2016). Likert Scales: CPSC 681-Topic Report. Poincare $1-11$

Betts MW, Maschner HDG, Schou CD, Schlader R, Holmes J, Clement N, Smuin M (2011) Virtual zooarchaeology: Building a web-based reference collection of northern vertebrates for archaeofaunal research and education. J Archaeol Sci 38(4):755.e1-755.e9. https:// doi.org/10.1016/j.jas.2010.06.021

Boessneck J, Müller HH, Teichert M (1964) Osteologische Unterscheidungsmerkmale zwischen Schaf (Ovis aries Linné) und Ziege (Capra hircus Linné). Kühne Archiv 22:157-181

Boyer DM, Gunnell GF, Kaufman S, McGeary TM (2017) Morphosource: Archiving and Sharing 3-D Digital Specimen Data. Paleontol Soc Pap 22:157-181. https://doi.org/10.1017/scs. 2017.13; https://www.morphosource.org/. Accessed 23 July 2019

Çakirlar C, Scheele EE, van den Hurk, Y, (2016), "Groningen Zooarchaeological Collections 2016: Vertebrates". https://hdl. handle.net/10411/20702. DataverseNL, V3. Accessed 23/07/2019

Champion E (2016) The Missing Scholarship behind Virtual Heritage Infrastructure, in 14th Eurographics Workshop on Graphics and Cultural Heritage, Heritage Communications session. GCH, Genova, Italy

Claessens L, Edwards S, Drake A, Eckardt M, Krzyzak M (2009) Aves 3D: a new online resource for the skeletal anatomy of extant and extinct birds. J Vertebr Paleontol 29:79A-79A https://aves3d.org/

Deb, S., \& Ray, A. B. (2016). Smartphone Based Virtual Reality Systems in Classroom Teaching -a study on the effects of learning outcome. 2016 IEEE Eighth International Conference on Technology for Education (T4E), (978), 68-71. https://doi.org/ 10.1109/T4E.2016.21

Erolin C, Jarron M, Csetenyi LJ (2017) Zoology 3D: Creating a digital collection of specimens from the D'Arcy Thompson Zoology Museum. Digital Appl Archaeol Cul Herit 7(September):51-55. https://doi.org/10.1016/j.daach.2017.11.002

Eve S (2012) Augmenting Phenomenology: Using Augmented Reality to aAida Archaeological Phenomenology in the Landscape. J Archaeol Method Theory 19(4):582-600. https://doi.org/10.1007/s10816012-9142-7

Fairnell E, Orton DC (2017) National Zooarchaeological Reference Resource (NZRR) [data-set]. Archaeology Data Service [distributor, York. https://doi.org/10.5284/1043267

Forte (2000) About virtual archaeology: disorders, cognitive interactions and virtuality. In: Barcelo J, Forte M, Sanders D (eds) Virtual reality in archaeology, Oxford, ArcheoPress. BAR International Series S 843:247-263

Forte M (2014). Virtual Reality, Cyberarchaeology, Teleimmersive Archaeology. In: Remondino F, Campana S (eds) 3D Recording and Modelling in Archaeology and Cultural Heritage: Theory and best practices (pp. 113-127). BAR

Gillis R, Chaix L, Vigne JD (2011) An assessment of morphological criteria for discriminating sheep and goat mandibles on a large prehistoric archaeological assemblage (Kerma, Sudan). J Archaeol Sci 38:2324-2339

Halstead P, Collins P, Isaakidou V (2002) Sorting the sheep from the goats: Morphological distinctions between the mandibles and mandibular teeth of adult Ovis and Capra. J Archaeol Sci 29:545-553

Helmer D \& Rocheteau M (1994) Atlas du squelette appendiculaire des principaux genres holocènes de petits ruminants du nord de la Méditerranée et du Proche-orient (Capra, Ovis, Rupicapra, Capreolus, Gazella). Edition APDCA, Antibes

Huggett J. (2004) The past in bits: towards an archaeology of information technology. Internet Archaeology, 15.

Jansen Y, Dragicevic P, Isenberg P, Alexander J, Karnik A et al (2015) Opportunities and Challenges for Data Physicalization. In: Proceedings of the ACM Conference on Human Factors in 
Computing Systems (CHI). ACM, New York. https://doi.org/10. 1145/2702123.2702180.Hal-01120152

Kersten TP \& Lindstaedt M (2012) Image-Based Low-Cost Systems for Automatic 3D Recording and Modelling of Archaeological Finds and Objects. In: Ioannides M, Fritsch D, Leissner J, Davies R, Remondino F, Caffo R (eds) Progress in Cultural Heritage Preservation. EuroMed 2012. Lecture Notes in Computer Science, vol, vol 7616. Springer, Berlin, Heidelberg. https://doi.org/10.1007/ 978-3-642-34234-9_1

Kvamme KL (1999) Recent Directions and Developments in Geographical Information Systems Author (ed): Kenneth L . Kvamme Published by : Springer Stable URL : http:// www.jstor.org/stable/41053168 REFERENCES Linked references are available on JSTOR for this article. J Archaeol Res 7(2):153-201

Likert R (1932) A tTechnique for the mMeasurement of Aattitudes. Arch Psychol 140:1-55

Lange AG (ed) 2004 Reference Collections: Foundation for Future Archaeology. Proceedings of the international conference on the European electronic Reference Collection May 12--13, 2014, Rijksdienst voor het Oudheidkundig Bodemonderzoek., Amersfoort, The Netherlands

Lock G (2009) Archaeological computing then and now: theory and practice, intentions and tensions. Archeologia e Calcolatori 20:7584

Luckin R, Bligh B, Manches A, Ainsworth S, Crook C, \& Noss R (2012) Decoding Learning: Promise and Digital Education

Maschner HDG, Betts MW, \& Schou CD (2011). Virtual zooarchaeology of the Arctic project (VZAP). The SAA Archaeological Record, (January), 41-43.

Maschner HDG, \& Schou CD (2013). Virtualization and the democratization of science: 3D technologies revolutionize museum research and access. Proceedings of the DigitalHeritage 2013 - Federating the 19th Int'1 VSMM, 10th Eurographics GCH, and 2nd UNESCO Memory of the World Conferences, Plus Special Sessions From CAA, Arqueologica 2.0 et Al., 2, 265-271. https://doi.org/10. 1109/DigitalHeritage.2013.6744763

Nicolae C, Nocerino E, Menna F, Remondino F (2014) Photogrammetry applied to problematic artefacts. International Archives of the Photogrammetry. Remote Sens Spat Inf Res - ISPRS Arch 40(5): 451-456. https://doi.org/10.5194/isprsarchives-XL-5-451-2014

Niven L, Steele TE, Finke H, Gernat T, Hublin J-J (2009) Virtual skeletons: using a structured light scanner to create a $3 \mathrm{D}$ faunal comparative collection. J Archaeol Sci 36(9):2018-2023. https://doi.org/10. 1016/j.jas.2009.05.021

Nieuwhof A 2004 Synopsis of conference discussions. In Lange (ed) Reference collections: foundation for future archaeology : proceedings of the international conference on the european electronic reference collection, may 12--13, 2004, ROB, amersfoort, the netherlands. Amersfoort: Rijksdienst voor het Oudheidkundig Bodemonderzoek.

Orton C. 2004. Some thoughts on the history of reference collections in the UK. In Lange (ed) Reference collections : foundation for future archaeology : proceedings of the international conference on the european electronic reference collection, may 12--13, 2004

Payne S (1985) Morphological distinctions between the mandibular teeth of young sheep, Ovis, and goats, Capra. J Archaeol Sci 12:139-147

Perry, S., Economou, M., Young, H., Roussou, M., \& Pujol, L. (2018). Moving beyond the virtual museum: eEngaging visitors emotionally. Proceedings of the 2017 23rd International Conference on Virtual Systems and Multimedia, VSMM 2017, 2018-January, 1-8. https:// doi.org/10.1109/VSMM.2017.8346276
Picavet, V, Brédif, M, Konini, M., Devaux, A. (2016). iTowns, framework web pour la donnée géographique 3D. Revue XYZ $\mathrm{N}^{\circ} 147$, 49.

Pilaar Birch SEP, Scheu A, Buckley M, Çakırlar C (2018) Combined osteomorphological, isotopic, aDNA, and ZooMS analyses of sheep and goat remains from Neolithic Ulucak. Archaeological and Anthropological Sciences, Turkey, pp 1-13

Potenziani M, Callieri M, Dellepiane M, Corsini M, Ponchio F, Scopigno R (2015) Computers \& Graphics 52:129-141

Prummel W \& Frisch HJ (1986) A guide for the distinction of species, sex and body side in bones of sheep and goat. J Archaeol Sci 13:567577

Richards J (2004) Do reference collections have an electronic future. In: Lange (ed) Reference collections : foundation for future archaeology : proceedings of the international conference on the european electronic reference collection, may 12-13, 2004, ROB, amersfoort, the netherlands. Rijksdienst voor het Oudheidkundig Bodemonderzoek, Amersfoort

Redding RW. 1984. Theoretical determinants of a herder's decisions: Modeling variation in the sheep/goat ratio. Animals and Archaeology 3. British Archaeological Reports: 161-170

Reinhard A (2018) Archaeogaming: an introduction to archaeology in and of video games. Berghahn Books, New York.

Roussou M., Perry S, Katifori A, Vassos S, Tzouganatou A, \& McKinney S (2019). Transformation through Provocation? Designing a 'Bot of Conviction' to Challenge Conceptions and Evoke Critical Reflection. In CHI '19 Proceedings of the 2019 CHI Conference on Human Factors in Computing Systems, Glasgow, Scotland, 4 9 May. New York: ACM. Paper No. 627. https://doi.org/10.1145/ 3290605.3300857

Ryder ML 1983. Sheep and man. Gerald Duckworth \& Co. Ltd.

Schmid E (1972) Atlas of animal bones for prehistorians, archaeologists, and quaternary geologists. Elsevier Science Publishers, Amsterdam

Schuetz M. (2016). Potree: Rendering large point clouds in web browsers. $\mathrm{Ph} . \mathrm{D}$. Thesis

Sullivan LP \& Childs TS (2003) Curating archaeological collections: from the field to the repository. Museum Anthropology. Altamira Press, Walnut Creek, CA

van Leusen M, \& Nobles GR. (2018). 3D Spatial Analysis: the Road Ahead. Proceedings of the 44th Annual Conference on Computer Applications and Quantitative Methods in Archaeology, 471-478.

Vigne JD \& Helmer D (2007) Was milk a "secondary product" in the Old World Neolithisation process? Its role in the domestication of cattle, sheep and goats. Anthropozoologica 42:9-40

YourDictionary (2019) https://www.yourdictionary.com/bonify. Accessed 11 May 2019

Zeder MA \& Hesse B (2000) The initial domestication of goats (Capra hircus) in the Zagros Mountains 10,000 years ago. Science 287: 2254-2257

Zeder MA \& Lapham HA (2010) Assessing the reliability of criteria used to identify postcranial bones in sheep, Ovis, and goats, Capra. J Archaeol Sci 37:2887-2905

Zeder MA \& Pilaar S (2010) Assessing the reliability of criteria used to identify mandibles and mandibular teeth in sheep, Ovis, and goats, Capra. J Archaeol Sci 37:225-242

Publisher's note Springer Nature remains neutral with regard to jurisdictional claims in published maps and institutional affiliations. 